\title{
Foucault e a história da filosofia
}

\author{
SALMA TANNUS MUCHAIL
}

RESUMO: Foucault faz filosofia investigando a história, mas não escreve uma "história da filosofia". Não exclui, entretanto, a abordagem dos filósofos: permeando os escritos sobre diferentes “objetos", inscreve-se, como que "em meio a eles", a leitura das filosofias. Pode-se destacar algumas passagens específicas e, a título de ilustração, exemplificar o modo foucaultiano de leitura dos filósofos. Por outro lado, Foucault também não toma por tema uma reflexão sobre a história da filosofia. Entretanto, uma aproximação com autores que realizam esta reflexão permite estabelecer algumas diferenças e semelhanças e entender que as histórias que Foucault escreve - permeadas de abordagens de filósofos - é investida de natureza filosófica.

freqüente que filósofos tomem a história da filosofia como via ou como tema de sua própria elaboração filosófica. Como via, quando se dedicam à leitura filosófica de filosofias já constituídas e, neste sentido, escrevem histórias da filosofia ou a praticam no estilo das monografias. Como tema, quando colocam questões acerca da natureza da história da filosofia e do modo adequado de ler filósofos e, neste sentido, fazem algo como uma teoria ou uma filosofia da história da filosofia. Recorrem, quase sempre, aos dois procedimentos. Digamos, logo de partida, que Michel Foucault não se ocupa com nenhum deles.

Quanto ao primeiro procedimento, ele, que faz filosofia escrevendo histórias, não escreve história da filosofia. Se são diversos os “objetos”, por assim dizer, de suas investigações históricas (loucura, medicina, ciências humanas, prisões, sexualidade, etc.), não há nenhuma que eleja como “objeto" as filosofias. Entretanto, a abordagem delas está presente. Diretamente, em
UNITERIMOS:

história, história da filosofia, leitura interna, leitura externa, leitura filosófica, Foucault.
Professora do Departamento de Filosofia da PUC-SP 
alguns poucos escritos, "avulsos", digamos assim, e sempre curtos (é o caso, por exemplo de Nietzsche, a genealogia e a história, ou do estudo sobre textos de Kant no curso sobre $O$ que é o iluminismo). Mas é também e sobretudo nos grandes livros que se inscreve, como "em meio" aos diferentes "objetos", a leitura de filosofias. Assim, com pesos e dosagens variadas, ela permeia praticamente todos eles: ora mais esporadicamente ou limitada a poucas referências (como é o caso de O nascimento da clínica e Vigiar e punir); ora ao longo de todo o livro, dispersamente (como em História da loucura) ou assiduamente (como em As palavras e as coisas), ora inerente à composição do livro (como a recorrência, entre outros, de Platão, Aristóteles, Xenefon, Plutarco, Sêneca, em $O$ uso dos prazeres e $O$ cuidado de si). Um estudo mais exaustivo sobre a abordagem foucaultiana de filosofias demandaria, portanto, que se a recolhesse ao longo de todos os seus escritos, relidos sob esta ótica. Limitemo-nos, por ora, a destacar apenas uma situação de exemplo.

Tomemos da Primeira Parte de História da loucura o trecho que inicia o capítulo II (Le Grand Renfermement) (cf. Foucault, 1972, p. 56-59). Trata-se ali de um daqueles momentos - freqüentes na escrita de Foucault - em que a exposição se detém não mais em um período histórico determinado e não ainda em outro, mas no limiar de intersecção, região fronteiriça que ao mesmo tempo demarca a separação e autoriza a passagem entre um período e o seguinte. Assim, depois do capítulo I (Stultifera Navis), que descrevera a loucura no período renascentista, trata-se agora de estabelecer a travessia para a idade clássica. E ela se configura em um confronto entre Montaigne e Descartes. Resumamos a passagem.

Em Montaigne, a crítica à presunção da razão. A leitura de um capítulo dos Ensaios mostra que, após distinguir o homem de razão do homem comum, este último digno de pena, Montaigne "um pensador", afirma ser ele também "merecedor de piedade" (cf. Montaigne, 1973, p. 94; Foucault, 1972, p. 57): posto que os julgamentos dos homens de razão se contradizem, seria loucura confiar unicamente na medida da inteligência e desprezar o que não conseguimos compreender; posto que jamais se está certo de nossos próprios julgamentos ou "jamais certo de não se estar louco" (cf. Foucault, 1972, p. 58), loucura é fiar-se só na razão. Assim, sem limite absoluto entre verdade e falsidade, a loucura embarca na trajetória em busca da verdade: como os loucos nas naus.

Em Descartes, a leitura da primeira Meditação mostra, ao contrário, a exclusão da loucura do caminho da dúvida em direção à certeza. Um paralelo entre os sentidos e os sonhos, por um lado, e a loucura por outro, revela entre eles "um desequilíbrio fundamental" (cf. Foucault, 1972, p. 57). Com efeito, os erros dos sentidos e as ilusões dos sonhos se incorporam aos passos daquele percurso; posto que não atingem a verdade objetiva das coisas, poderão ser posteriormente recuperados depois que se alcançar, na segunda Meditação, a segurança do cogito; incluem-se assim, no trajeto do pensamento que conduz à certeza do próprio pensamento. Não é o que ocorre 
com a loucura. "E como poderia eu negar que estas mãos e este corpo são meus? A não ser talvez que eu me compare a estes insensatos cujo cérebro está de tal modo perturbado e ofuscado pelos negros vapores da bile que constantemente asseguram que são reis quando são muito pobres, que estão vestidos de ouro e de púrpura quando estão inteiramente nus, ou imaginam ser cântaros ou ter um corpo de vidro. Mas quê? São loucos e eu não seria menos extravagante se me guiasse por seus exemplos" (cf. Descartes, 1962, p. 110118; Foucault, 1972, p. 56-57). Porque é "condição de impossibilidade do pensamento" (Foucault, 1972, p. 57), a loucura afeta a verdade objetiva do sujeito que é sujeito pensante. Se penso, existo; se sou louco, não penso; portanto, se penso não sou louco e se sou louco nem penso nem existo. "Entre Montaigne e Descartes, [escreve Foucault], um acontecimento se passou: algo que concerne ao advento de uma ratio" (1972, p. 58). Estabelecida a divisão entre razão e desrazão, tem lugar o banimento da loucura: lugar de exílio, como os loucos no Hospital Geral.

Como se vê, a reconstituição foucaultiana destas passagens filosóficas dispõe-se, na construção do seu próprio discurso, como estratégia de transição entre o século XVI e o XVII. Não é uma leitura isolada de discursos filosóficos: atraca-os ao derradeiro porto renascentista e avizinha-os da divisória inaugural da idade clássica. Assim, a passagem que acabamos de resumir poderia igualmente caber sob dois sub-títulos, se eventualmente lhe quiséssemos atribuir algum: "De Montaigne a Descartes" ou "Da Nau ao Hospital".

Ampliando os contornos deste exemplo, pode-se dizer que as abordagens de discursos filosóficos nos escritos de Foucault, desde as mais episódicas às mais regulares, se não lhes confere qualquer privilégio enquanto "objetos" para uma investigação histórica específica, insere-os, contudo, tanto em redes inter-discursivas, enquanto elementos constitutivos de uma épistémê, quanto nas articulações com práticas ou instituições sociais, enquanto integrantes de um "dispositivo" de poder, seja como peças de sustentação, seja como instrumentos de luta.

Quanto ao segundo procedimento, isto é, uma reflexão sobre a natureza e o método apropriado da história da filosofia, também não constitui preocupação particular de Foucault. Uma tematização desta questão, se fosse elaborada, haveria de ajustar-se, sem dúvida, às tematizações sobre a natureza e os procedimentos de suas investigações, explicitadas não somente no livro A arqueologia do Saber como em tantas passagens integradas aos vários livros, artigos, entrevistas. Mas esta é também uma hipótese que demanda um estudo mais longo. No momento, limitemo-nos apenas ao levantamento de alguns indícios, pela via das aproximações e diferenças, tomando algumas descrições de método em história da filosofia como situação de referência.

Ao propor o chamado método estrutural para a leitura das filosofias, Guéroult o situa como um determinado tipo de história "vertical" que, pela sua feição filosófica, respeita, internamente, a natureza dos seus objetos ${ }^{1}$. Não é difícil compreender que a leitura foucaultiana não se prende à construção
${ }^{1}$ Referimo-nos aqui, particularmente ao texto de M. Guéroult (1974, p. 7-19). 
${ }^{2}$ Veja-se, por exemplo, de Merleau-Ponty, Partout et nulle part (1960b, p. 158-200) e Le philosophe et son ombre (1960a, p. 201228). arquitetural dos sistemas filosóficos, cujos encadeamentos lógicos permitem reconstituí-lo segundo sua “ordem de razões”. Isto não significa que análises detalhadas de textos sejam desprezadas. Reportemo-nos àquela passagem sobre Montaigne e Descartes. Como se sabe, ela foi alvo de críticas, primeiro de $\mathrm{H}$. Gouhier, e incisivamente, de Derrida (1963). Ora, na resposta a este último, Foucault (cf. 1971) contempla o escrito cartesiano com o exame meticuloso, quase requintado, de palavras, tempos de verbos, imagens, disposição textual, etc. Faz ver, já pelo seu título, que as Meditações requerem não só a leitura que encontra o encadeamento sistemático de demonstrações, como aquela que as apreende como exercício, prática discursiva. E, ao final, não sem mordacidade, afirma que a estrita redução dos discursos aos seus aspectos textuais é aliada ao ponto de vista globalizador do sistema e tributária da metafísica.

Mas Guéroult identifica um outro tipo de história "vertical" da filosofia, também de feição filosófica, que, privilegiando a interioridade do autor, caracteriza-se pela busca de origens e intenções. Por semelhança de orientação, podemos assemelhá-la à proposta de Merleau-Ponty para a leitura das filosofias. Trata-se de descobrir por sob os textos os sentido que subjaz a eles e anima o processo de elaboração filosófica, sentido implícito que, por isto mesmo, nos exige atentos não só ao filósofo como à sua sombra, e nos conduz a pensar o "impensado" " 2 A leitura foucaultiana, muito ao contrário, não se reconhece na suposição do "não-dito". Voltada que é para a positividade do acontecimento discursivo e suas relações inter e extra-discursivas, afasta-se das perspectivas que acenam para as filosofias da consciência.

Poder-se-ia perguntar então se o modo foucaultiano de ler filosofias não se classificaria no método que Guéroult nomeia de história "horizontal". Mais histórico e pouco filosófico, consiste em expor a sucessão temporal das filosofias e sua contextualização em circunstâncias sociais, políticas, econômicas, etc., condições externas do seu surgimento. Longe disto, a inclusão das filosofias em conjuntos heterogêneos de saberes e práticas sociais, nada tem de comum com causas ou explicações exteriores. Na configuração de um solo epistemológico ou de um dispositivo estratégico, os componentes são tão constituídos quanto constituintes e entre eles não há relações nem de causa e efeito nem de "exterioridade" e "interioridade".

Todavia, entre os métodos descritos como história "vertical" e a postura de Foucault é possível talvez esboçar um traço de semelhança. À leitura estrutural de Guéroult não interessa apenas o conhecimento dos sistemas filosóficos, senão também a instigação de que este conhecimento é capaz para a reflexão filosófica presente; a leitura intencional de Merleau-Ponty, por sua vez, quer repensar as filosofias historicamente dadas, na direção de provocar um pensamento novo. Ora, as investigações históricas de Foucault, precisamente por sua dimensão genealógica, debruçam-se sobre o passado para elucidar o presente relativamente às diferenças com o que o precede $\mathrm{e}$ para mobilizá-lo relativamente às diferenças que, introduzidas por nossa intervenção, o poderão suceder. 
Esta observação permite que evoquemos, de passagem, mais uma proposta sobre a questão da história da filosofia, da qual a leitura foucaultiana estará provavelmente mais próxima. Trata-se de algumas reflexões de F. Châtelet (cf. 1977, p. 23-42) de que realçamos dois aspectos: primeiro, a afirmação de que pela referência ao passado pensamos nossa atualidade através do "diferencial"; segundo, a proposição de uma história da filosofia, hoje, que explicite as conexões das filosofias com a política, que, em termos foucaultianos, remete às relações que elas mantêm com regimes de poder, quer como reforço, quer como resistência.

Para concluir, uma hipótese genérica. Na medida em que a abordagem das filosofias só se compõe esparsamente, há menos que história da filosofia nas investigações históricas de Foucault; e no entanto, há mais, na medida em que, nelas, é toda a história que se acha investida de feição filosófica.

Recebido para publicação em maio/95

MUCHAIL, Salma Tannus. Foucault and the history of philosophy. Tempo Social; Rev. Sociol. USP, S. Paulo, 7(1-2): 15-20, october 1995.

ABSTRACT: Foucault generates philosophy by investigating history, but is not the author of a "history of philosophy". He does not exclude, however, the philosophical approach: within the texture of his writings on several objects, one finds the thread of a reading of philosophies. Certain specific passages can be pointed out which, by way of illustration, exemplify the Foucaultian reading of philosophers. On the other hand, Foucault does not choose as subject matter a reflection on the history of philosophy. Nevertheless, an approximation with authors who carry out such a reflection allows us to establish certain differences and similarities and to understand that the histories which Foucault writes - pervaded by the approaches of and to philosophers - is vested with a philosophical nature.

\section{REFERÊNCIASBIBLOGRÁFCAS}

Châtelet, F. (1977) A questão da história da filosofia hoje. In: Châtelet, Derrida, Foucault, Lyotard e Serres. Políticas da filosofia. Textos reunidos por D. Grisoni, trad. de J. Saramago. Lisboa, Moraes.

Derrida. (1963) Cogito e história da loucura. Conferência.

Descartes. (1962) Meditações. In: .Obra Escolhida. Trad. de J.
UNITERIMS:

history,

history of philosophy, internal reading, external reading, philosophical reading, Foucault. 
Guinsburg e Bento Prado Júnior. São Paulo, Difusão Européia do Livro.

Foucault, Michel. (1971) Mon corps, ce papier, ce feu. In: . Histoire de la folie à l'âge classique. Anexo à $2^{\mathrm{a}}$ ed. Paris, Gallimard, 1972. . (1972) Histoire de la folie à l'âge classique. $2^{\mathrm{ème}}$ éd. Paris, Gallimard.

GuÉroult, M. (1974) La méthode en histoire de la philosophie. Philosophiques, Paris, vol. 1, nº 1 , avril.

Merleau-Ponty. (1960a) Le philosophe et son ombre. In: . Signes. Paris, Gallimard. . (1960b) Partout et nulle part. In: . Signes. Paris, Gallimard.

Montaigne. (1973) Ensaios. Trad. de S. Milliet. Col. “Os Pensadores”. São Paulo, Abril Cultural. 